\title{
The Formulation of Epistemological Disjunctivism
}

\author{
Forthcoming in Philosophy and Phenomenological Research ${ }^{*}$ \\ Craig French \\ University of Cambridge
}

\begin{abstract}
I argue that we should question the orthodox way of thinking about epistemological disjunctivism. I suggest that we can formulate epistemological disjunctivism in terms of states of seeing things as opposed to states of seeing that $p$. Not only does this alternative formulation capture the core aspects of epistemological disjunctivism as standardly formulated, it has two salient advantages. First, it avoids a crucial problem that arises for a standard formulation of epistemological disjunctivism - the basis problem. And second, it is less committed than standard formulations are in the metaphysics of perception.
\end{abstract}

\section{What is Epistemological Disjunctivism?}

Epistemological disjunctivism concerns the nature of the rational support we get from certain cases of perceptual experience. Like perceptual disjunctivism (see Snowdon (2005), Martin (2006)), epistemological disjunctivism involves a negative claim underpinned by a positive claim. To see how this works, let's first consider a position which contrasts with epistemological disjunctivism. (Note that as others do, I'll here be understanding epistemological disjunctivism just as a thesis about the rational support provided by visual perceptions.)

\footnotetext{
${ }^{*}$ For helpful comments on an earlier draft thanks to Tom Avery, Chris Jay, Mark Eli Kalderon, Bence Nanay, Jens Van 't Klooster and Lee Walters, and for helpful general discussion thanks to Clayton Littlejohn and Aidan McGlynn. A version of this paper was given at the Edinburgh Epistemology Research Seminar, thanks to the audience on that occasion for very helpful questions and comments, especially Jie Gao, Jesper Kallestrup, Christopher Ranalli, and Duncan Pritchard.
} 
Take a fully veridical experience which is a genuine perception of a lemon before me. And let's suppose that this experience provides me with rational support for the belief that there is a lemon before me. That is to say, it provides me with epistemic justification or warrant of some variety to believe that there is a lemon before me. (Call this the "Good" Case, as it involves a fully veridical experience with genuine perceptual contact with an object). But now take a subjectively indistinguishable hallucinatory experience as of a lemon before me, where there is no such lemon there (and hence no perceptual contact with a lemon). And let's suppose that this experience also provides me with rational support of some kind for the belief that there is a lemon before me. (Call this the "Bad" Case, as it involves a defective exercise of the general capacity I have for sensory experience - I have an experience but I don't make perceptual contact with my environment).

Now in one sense the rational standings I have in these different cases of experience are the same. They are both rational standings, and moreover rational standings with the same target belief (content). That is, they are both rational standings which epistemically justify or warrant the belief that there is a lemon there. So, at this generic level at least, the rational standings are alike, similarly to how at the generic level the experiences I have are alike (they are both sensory experiences, and moreover, both sensory experiences as of a lemon).

A further thing we might hold about the rational standings involved in these different cases is that they are the same in some more specific or fundamental way. That is, we might think that the rational support that I have in the Good Case is of the same fundamental sort as the rational support I have in the Bad Case, we might think, that is, that the rational standings have the same nature. This is to endorse a sort of common kind thesis regarding Bad Case and Good Case rational support (on common kinds, see Martin (2006)). What more specifically might one say about this alleged common kind?

In the Bad Case I have rational support to believe that there is a lemon before me, even when that is not the case. Thus, whatever else we might say about the nature of the rational standing in the Bad Case, we have to say at least this: the specific kind of rational support present in the Bad Case is such that it can obtain even when the supported belief is false. It is then not essential to the rational support in the Bad Case that it is factive, that it requires the truth of what it supports. So if the rational support had in the Good Case is fundamentally like the rational support had in the Bad Case then even in such a case it won't be of the nature of such rational support that it is factive. The negative condition has to apply even to the rational support present in the Good Case. Thus the specific kind of rational support one has even in the Good Case - where one's belief is in fact true - is such that its obtaining doesn't require the truth of the 
belief it rationally supports.

According to the common kind claim it is held that Bad Case and Good Case rational support are fundamentally the same, and thus not in their nature factive.

Epistemological disjunctivism involves a negative claim - the denial of the common kind thesis - underpinned by a positive claim. Thus, Duncan Pritchard, who has in recent work done a lot to clarify and develop epistemological disjunctivism, states that epistemological disjunctivism is

the rejection of idea that the... rational support one possesses in favour of one's perceptual belief is the same regardless of whether one is having a normal veridical perceptual experience as opposed to being the victim of an introspectively indistinguishable experience which is in fact deceptive or untrustworthy in some way (e.g., a hallucination) (2011, p. 434).

[The] two rational standings are radically different in kind (this is what makes this epistemological proposal disjunctivist) (2012, p. 16).

We can thus put the negative strand of epistemological disjunctivism in this way:

\section{The Negative Claim}

The rational support in the Good and Bad Cases are not of the same nature or fundamental kind.

Epistemological disjunctivism also involves a positive thesis which underlies the negative claim. Pritchard puts the positive thesis like this:

\section{The Core Thesis}

In paradigmatic cases of perceptual knowledge an agent, $S$, has perceptual knowledge that $\phi$ in virtue of being in possession of rational support, $R$, for her belief that $\phi$ which is both factive (i.e. $R$ 's obtaining entails $\phi$ ), and reflectively accessible to $S$ (2012, p. 13).

A paradigmatic case of perceptual knowledge is one where that knowledge is grounded in a perfectly veridical case of perception. The nature of the rational support provided by these cases of perception, the Core Thesis tells us, is such that it is reflectively accessible, and factive. 
How does this positive claim underpin the Negative Claim mentioned above? Here, factivity is doing the work (I'll return to the reflective accessibility aspect shortly). To say that a kind of rational support is factive is to say that if rational support of that specific kind obtains then it must be that the supported belief is true. So the Core Thesis tells us that in a perfectly veridical experience as of a lemon before me, say, the rational support to believe that there is a lemon before me I have is, of its nature, factive. Rational support of that specific kind just can't obtain unless there is a lemon there before me. But now consider the rational support I have in a subjectively indistinguishable but non-veridical hallucinatory experience. As noted above, such rational support is not, in its nature, factive. Thus, given the Core Thesis, Bad Case rational support thus differs in fundamental kind to Good Case rational support. To simplify: if the Core Thesis is true, then given the facts about Bad Cases, the Negative Claim follows.

The view we have outlined so far is quite generic. But epistemological disjunctivism is standardly understood in a yet more specific way. Once again we can draw on Pritchard's helpful presentation, and we can put the further specification of the Core Thesis, like this:

\section{The Specification}

The particular kind of rational support that the epistemological disjunctivist claims that our beliefs enjoy in paradigm cases of perceptual knowledge is that provided by seeing that the target proposition obtains. So when one has paradigmatic perceptual knowledge of a proposition, $p$, one's reflectively accessible rational support for believing that $p$ is that one sees that $p$ (p. 14).

What I want to highlight concerning this further specification is that the epistemological disjunctivist holds that the visual perceptual states which ground perceptual knowledge, that is, the visual perceptual states which are at the heart of the epistemological disjunctivist's epistemology of perception, are states of seeing that $p$. I take it the idea is that we are to view such states as constituting the rational support for belief had in paradigm cases of perceptual knowledge. If we assume that such states are factive and reflectively accessible, then this works just fine as a specification of the Core Thesis, and gives us a more complete version of epistemological disjunctivism.

To summarize, epistemological disjunctivism involves a negative claim underwritten by a positive claim. In my presentation there are three elements that make up the view: (1) The Negative Claim. This is the denial of the common 
kind thesis: that is, it is the denial of the claim that Good Case and Bad Case rational support are of the same non-factive nature. This is underwritten by a positive claim. In its generic form, this is (2) the Core Thesis: rational support in paradigmatic cases of perceptual knowledge is, in its nature, reflectively accessible and factive. And in its specific form this is what I've called (3) The Specification: reflectively accessible rational support in paradigmatic cases of perceptual knowledge is constituted by states of seeing that $p$ (a specific kind of factive state).

There may be other ways of developing epistemological disjunctivism, but this, it seems to me, captures the core elements of the standard version of the view. For instance, McDowell, the most prominent proponent of epistemological disjunctivism, can be read as committed to epistemological disjunctivism in this sense (see e.g., McDowell (1982, 1995, 2008)).

McDowell's epistemological disjunctivism comes about in his rejection of a highest common factor conception of perceptually grounded rational support, based on a certain positive conception of the rational support we have in Good Cases. So take Good Case and Bad Case experiences respectively, McDowell thinks that '[e]xperiences of the first kind have an epistemic significance that experiences of the second kind do not have' (2008, p. 381). And this is because in the Good Case, McDowell thinks, one has rational support which is in its nature factive. On McDowell's view, in the Good Case, one has rational support constituted by an experience which involves a fact, $p$, itself:

But we are not to accept that in non-deceptive cases [i.e., Good Cases] too the object of experience is a mere appearance, and hence something that falls short of the fact itself. On the contrary, the appearance that is presented to one in those cases is a matter of the fact itself being disclosed to the experiencer (1982, p. 387).

If the kind of rational support for $p$ in the Good Case is constituted by an experience in which the fact that $p$ is itself directly manifest to $S$, then rational support of that kind just could not obtain in a situation where it is not the case that $p$. Such rational support is thus in its nature factive. This is a point that McDowell puts in different ways. For instance, he sometimes puts it in terms of the indefeasibility:

When one's perceptual faculties "engage the material world directly", as Wright puts it, the result-a case of having an environmental state of affairs directly present to one in experience-constitutes one's being justified in making the associated perceptual claim. It is 
hard to see how any other kind of justification could have a stronger claim to the title "canonical". And this justification is not defeasible. If someone sees that $\mathrm{P}$, it cannot fail to be the case that P (2008, pp. 383-384).

And sometimes he puts the idea in terms of perceptual states being "guaranteeing" informational states; that is, attitudes to $p$ which require the truth of $p$ (an idea he explicitly links to factivity in 1995, p. 402, fn. 10). However we put it, the idea is clear. The rational support for $p$ that we have in Good Cases of visual perception is, unlike whatever rational support we might have in Bad Cases, such as to entail $p$. I'll continue to put this in terms of the idea that such rational support is in its nature factive.

So given McDowell's positive conception of Good Case rational support, and the fact that Bad Case rational support is not in its nature factive, McDowell is obliged to view Bad Case and Good Case rational support as fundamentally different. So McDowell is obliged to reject the common kind thesis. And this is exactly what he does in rejecting what he calls a 'highest common factor' conception of experientially grounded rational support.

So far, then, it seems fair to say that McDowell is committed to the Negative Claim, and to that aspect of the Core Thesis which has it that Good Case rational support is factive. Moreover, in line with the The Specification McDowell is happy to conceive of the fact involving visual experiences at the heart of his epistemological disjunctivism in terms of states of seeing that $p$. Thus in Mind and World talk of openness to facts, and facts being manifest in visual experience is run together with talk of seeing that such-and-such is the case:

in enjoying an experience one is open to manifest facts, facts that obtain anyway and impress themselves on one's sensibility. (At any rate one seems to be open to facts, and when one is not misled, one is.)... when we see that such-and-such is the case, we, and our seeing, do not stop anywhere short of the fact. What we see is: that such-and-such is the case (1994, p. 29).

Finally, McDowell takes it that the factive rational support we have in Good Cases must be reflectively accessible to one. This falls out of perspective on knowledge in general that McDowell has, according to which knowledge is a standing in the space of reasons, and the claim that 'we lose the point of the space of reasons if we allow someone to possess a justification even if it is outside his reflective reach' (1993, p. 418, fn. 7). So the rational support for the visual perceptual knowledge I have must be reflectively accessible to me, 
within my reflective reach, on McDowell's view. But more specifically, McDowell thinks that it must be reflectively available to me in such a way that I am able to justify my knowledgeable belief should the opportunity arise (2011, p. 17). And I take it that being able to justify one's belief need not be a matter of being able to construct an elaborate inference, but just being able to offer a rational explanation of one's perceptual belief by citing one's perceptual state (e.g., by saying: I believe that there is a lemon before me because I can see that there is a lemon before me).

I mention this internalist aspect of McDowell's view just to complete the idea that McDowell can be read as an epistemological disjunctivist of the sort outlined in this section. There is obviously lots more to be said to get a full understanding of reflective accessibility, but since such details are not relevant to my discussion below, I'll set them aside here.

\section{Plan}

Here is the plan for the remainder. In the next section we'll see that there is a 'basis problem' that arises for epistemological disjunctivism. But it arises only given that disjunctivism is formulated in terms of seeing that $p$. That is, only given a formulation that includes The Specification. The problem comes about if we combine The Specification with a standard view of seeing that $p$. Pritchard tries to get around the problem by rejecting the standard view. But I'll question this rejection. In the subsequent section I'll suggest that this doesn't leave epistemological disjunctivism with a 'basis problem' if we are open to rejecting the The Specification, and instead formulating disjunctivism in terms of an alternative specification: in terms not of seeing that $p$ but rather in terms of seeing things.

\section{The Basis Problem}

First consider a standard view of seeing that $p$, which Pritchard puts like this:

seeing that $p$ just is a way of knowing that $p$ (i.e., it is knowing that $p$ via visual perception) (2012, p. 21).

This is a view we find in, for instance, Dretske (1969), Williamson (2000), and

Cassam (2009). But now Pritchard claims that this generates a problem for epistemological disjunctivism:

if this is indeed the right way to think about the relationship between seeing that $p$ and knowing that $p$, then it is hard to understand how 
seeing that $p$ could constitute one's epistemic basis for knowing that $p$. After all, on this view seeing that $p$ already presupposes knowledge that $p$ on account of how it is just a way of knowing that $p$. But how then could seeing that $p$ constitute one's epistemic basis for knowing that $p$ ? Call this the basis problem for epistemological disjunctivism (p. 21).

At the heart of epistemological disjunctivism as we've formulated it thus far is The Specification - the idea that seeing that $p$ is what constitutes rational support in paradigm cases of visual perceptual knowledge that $p$. If states of seeing that $p$ constitute rational support for such knowledge, it must be that such states form the basis of such knowledge. But how can seeing that $p$ be the basis of knowing that $p$ if seeing that $p$ already amounts to knowing that $p$ ? 'There doesn't seem to be sufficient distance between seeing that $p$ and knowing that $p$ for the former to properly be the basis of the latter. Thus epistemological disjunctivism seems to be in trouble. (For helpful discussion in a different context of some epistemic principles we might use to motivate this sort of problem see Cassam (2009)).

How should the epistemological disjunctivist respond to the basis problem? I won't survey the options here but rather launch straight into Pritchard's own suggested solution, which I want to query.

\section{Pritchard's Solution to the Basis Problem}

Pritchard argues that the epistemological disjunctivist can avoid the basis problem by rejecting the standard view of seeing that $p$, that is, by rejecting the claim that seeing that $p$ is just a specific way of knowing that $p$ (2012, p. 25). Now the standard view of seeing that $p$ is to be understood in such a way that it has as a consequence what we can call the Entailment Thesis:

\section{Entailment Thesis}

Seeing that $p$ entails knowing that $p$.

Like McDowell (2002, p. 277), Pritchard thinks that $S$ 's seeing that $p$ doesn't entail knowledge that $p$. Thus he rejects the Entailment Thesis, and hence rejects the standard view of seeing that $p$.

It is not as if Pritchard is recommending rejection of the idea that seeing that $p$ is an epistemically significant state. That would be to go too far, and indeed would hardly be consistent with epistemological disjunctivism. Again, like McDowell, Pritchard thinks that seeing that $p$ doesn't entail knowledge but rather puts $S$ in an excellent position to gain knowledge: 
a crucial distinction that we need to draw is between being in a state that guarantees knowledge and being in a state that guarantees that one is in a good position to gain knowledge, even if one is unable to properly exploit this opportunity. I want to suggest that seeing that $p$ is factive and robustly epistemic in the weaker latter sense rather than in the more robust former sense. That is, seeing that $p$ and knowing that $p$ come apart - such that the former can properly be thought of as providing an epistemic basis for the latter-and come apart in just those cases in which an agent, on account of seeing that $p$, is thereby in a good position to gain knowledge that $p$ and yet is unable to properly exploit this opportunity (p. 26).

In brief: Pritchard thinks that seeing that $p$ is 'robustly epistemic' in that it guarantees that one is in a good position to gain knowledge, but not in that it guarantees knowledge. Crucially, seeing that $p$ is now conceived to be sufficiently distinct from knowing that $p$ for there not to be a special problem about how it can be the basis of such knowledge.

So Pritchard rejects the Standard View of seeing that $p$ by rejecting the Entailment Thesis. In support of this negative contention Pritchard offers a case which we can call BARN:

Suppose, for example, that one is in a situation in which one is genuinely visually presented with a barn and circumstances are in fact epistemically good (there's no deception in play, one's faculties are functioning correctly, and so on). But now suppose further that one has been told, by an otherwise reliable informant, that one is presently being deceived (that one is in barn facade county, say), even though this is in fact not the case. Clearly, in such a case one ought not to believe the target proposition, and hence one cannot possibly know this proposition either... Does it follow that one does not see that the target proposition obtains?

Pritchard suggests that this does not follow, and in BARN $S$ can see that

(B) there is a barn there.

even though she doesn't know that $B$. And so the Entailment Thesis is false. But why does Pritchard think it is plausible that $S$ can see that $B$ even though she doesn't know that $B$ in this case? Well... 
suppose that one were to discover subsequently that the testimony one received was false, but that everything else one knows about the circumstances in which one was presented with this (apparent) barn remained the same. Wouldn't one now retrospectively treat oneself as having earlier seen that there was a barn? Think, for example, about how one would describe one's situation in this regard were one to be asked about it. Wouldn't it be most natural to say that one did see that there was a barn in the field, rather than to 'hedge' one's assertion by saying, for example, that one merely thought that one saw a barn? [...] But if that's right, then it does appear that there is good reason for supposing that one does see that there is a barn in this case, even though one can't know the target proposition, and even though one ought not to believe the proposition (and most probably won't believe it) (pp. 26-27).

\section{Critical Discussion}

Let's grant that $S$ doesn't know that $B$ in BARN. Pritchard thinks that $S$ nonetheless sees that $B$. Call this claim Pritchard's Verdict. Should we accept it? I will now offer up some resistance to Pritchard's reasons for suggesting that we accept it.

In BARN, $S$ enjoys successful visual perceptual contact with aspects of her environment (e.g., the barn, and perhaps some of its features). So in a sense, it is clear that $S$ sees what is before her eyes. To represent the perceptual facts about BARN adequately we need to ensure that we capture this fact. We might do so in a number of ways. For instance, we might hold that she saw a barn there, or that it looked to her as if there was a barn there - where that is in this case a veridical appearance grounded in the barn's being there - etc. But the truth and naturalness of these descriptions is consistent with her failing to see that $B$. Proponents of the Entailment Thesis can say that she does fail to see that $B$, because, given the deceptive conditions, she fails to know that $B$. Such proponents can still capture the manifest perceptual facts without appeal to states of the sort seeing that $p$.

This is just to say that it is difficult to support Pritchard's Verdict just by reflecting upon what we need to do to adequately capture the manifest perceptual facts about the case. But this is not yet to disagree with anything Pritchard says. For Pritchard doesn't argue that we need to appeal to what I'm calling Pritchard's Verdict to capture the manifest perceptual facts. His suggestion is rather that support for his verdict comes from these claims:

(1) A natural description for $S$ to give, once apprised of the facts about 
BARN, is: (P) "I saw that there was a barn there".

(2) (P) is a more natural description for $S$ to give, once apprised of the facts about BARN, than the hedged description: (Q) "I merely thought I saw a barn there".

Regarding (1) a defender of the Entailment Thesis might offer the following reply. They might first, in a concessive mood, agree that $(\mathrm{P})$ is a natural thing for $S$ to say, but then resist the idea that it, and therefore, Pritchard's Verdict, is true. The crucial question is why is $(\mathrm{P})$ a natural thing for $S$ to say? Is the only explanation of the naturalness of $(\mathrm{P})$ one which requires agreement with Pritchard's Verdict? No. A defender of the Entailment Thesis can suggest an alternative explanation: $(\mathrm{P})$ is a natural description of the case, for $S$, because it conveys visual perceptual success, which is a feature of the case. Insofar as $S$ conveys that she was in visual perceptual contact with her environment, in saying that she saw that $B$, the description is perfectly natural and conveys some truth. But, a defender of the Entailment Thesis can say that the description is ultimately false because it carries the implication that $S$ knew that $B$, which is false.

What of (2)? Pritchard draws a contrast between two descriptions:

(P) I saw that there was a barn there.

(Q) I merely thought I saw a barn.

Pritchard's idea is that we get support for his Verdict - which is embedded in (P) - since $(\mathrm{P})$ is a more natural thing for $S$ to say looking back on her situation, than (Q) is. I have two things to say in response to this. The first is an application of the idea operative in the reply to (1). Let's grant that $(\mathrm{P})$ is a more natural thing for $S$ to say than (Q). Why should this support the idea that $(\mathrm{P})$ is true? This is far from clear. For we might say this: there is a naturalness difference between $(\mathrm{P})$ and $(\mathrm{Q})$. But it is to be accounted for not in terms of the idea that $(\mathrm{P})$ is straightforwardly true, whereas $(\mathrm{Q})$ is false. Rather it is to be accounted for in terms of these differences: (a) (P) is false, but not clearly false, as it conveys some truth (that is, to do with visual perceptual success, as mentioned above), and (b) (Q) is false, and quite clearly so. That is, it is just obviously not so that $S$ merely thought she saw a barn, she did see one, this is part of the very setup of BARN.

The second thing to say here is that it is not as if $(\mathrm{P})$ and $(\mathrm{Q})$ exhaust the options. For, as noted above, there are different ways of representing perceptual success in BARN, not all of which imply $(\mathrm{P})$. For instance, it would be natural for $S$ to say 
(R) I saw a barn there.

This doesn't involve or imply $(\mathrm{P})$, and it is certainly more natural than $(\mathrm{Q})$. (R) is an option that needs to be on the table. The way Pritchard presents things here obscures the fact that we can reject both $(\mathrm{P})$ and $(\mathrm{Q})$. Having $(\mathrm{R})$ on the table allows us to wonder whether both $(\mathrm{P})$ and $(\mathrm{Q})$ are both false, whereas $(\mathrm{R})$ is true. Of course both $(\mathrm{R})$ and $(\mathrm{P})$ might be true, but we have to at least consider the option that only $(\mathrm{R})$ is true out of the two. That $(\mathrm{P})$ is more natural than $(\mathrm{Q})$ doesn't undermine the idea that only $(\mathrm{R})$ is true. I note this as an option for a defender of the Entailment Thesis, and to highlight how what Pritchard says doesn't appear to rule out this option. That is not to say that other considerations won't rule it out, but what are they? That is a question for one wanting to reject the Entailment Thesis.

It seems to me then that a proponent of the Entailment Thesis can give perfectly coherent and reasonable descriptions of the naturalness facts that Pritchard draws our attention to. Pritchard thus needs to say more if we are to take those facts to support the falsity of the Entailment Thesis, and hence a rejection of the standard view of seeing that $p$.

I have merely been offering up resistance to Pritchard's arguments on behalf of a defender of the Entailment Thesis. I think that the defender of the Entailment Thesis is on strong ground though. I won't argue for this here, as I have argued for it elsewhere (see French $(2012,2013)$ ). But let me briefly indicate why I think the defender of the Entailment Thesis is on strong ground. The reason is that it is built into the semantics of sentences of the form ' $S$ sees that $p$ ' (of the sort we are interested in here, e.g., $(\mathrm{P})$ ), that the Entailment Thesis holds. I have argued, partly on the basis of work in linguistics by Gisborne (2010), that part of what sentences of the form ' $S$ sees that $p$ ', of the perception-ascribing sort we are interested in, say is: there is some state of visual perception $v$, of which $S$ is the subject, and which is such that on the basis of $v, S$ knows that $p$. So part of what uses of $(\mathrm{P})$ say is: there is some state of visual perception $v$, of which I am the subject, and which is such that on the basis of $v$ I know that there is a barn there. Because of the semantics of the relevant sentence types, uses of such sentences are ascriptions of visual perception, but also of knowledge based on that visual perception. Thus the Entailment Thesis holds.

There is clearly much more to be said here about the Standard View and the Entailment Thesis (see e.g., the arguments against the Entailment Thesis in Turri (2010), and my reply in French (2012)), but absent further reasons to reject the standard view of seeing that $p$, we seem to be back with the basis problem for epistemological disjunctivism. 


\section{Summary}

Epistemological disjunctivism as we've encountered it so far is formulated in terms of seeing that $p$. That's what we get from: 


\section{The Specification}

The particular kind of rational support that the epistemological disjunctivist claims that our beliefs enjoy in paradigm cases of perceptual knowledge is that provided by seeing that the target proposition obtains. So when one has paradigmatic perceptual knowledge of a proposition, $p$, one's reflectively accessible rational support for believing that $p$ is that one sees that $p$.

We can now note that there are two versions of this:

The Specification + The Standard View

The Specification + the standard view of states of seeing that $p$ where that includes the Entailment Thesis.

\section{The Specification + The McDowell-Pritchard View}

The Specification + McDowell and Pritchard's understanding of states of seeing that $p$ where the Entailment Thesis doesn't hold.

Now the problem with epistemological disjunctivism formulated the first way is the basis problem. And the problem with epistemological disjunctivism formulated the second way is that we have as yet no evidence to suppose that there are states of seeing that $p$ which don't conform to the standard view of seeing that $p$.

In response to these issues we might think that epistemological disjunctivism is in trouble. But I don't think that. I think the issues should lead us to ask these crucial questions: why should we accept the McDowellian inheritance and formulate epistemological disjunctivism in terms of seeing that $p$ in the first place? Can we formulate epistemological disjunctivism without appealing to states of seeing that $p$ (on either of the understandings of such states we have encountered)? I'll argue that we can.

\section{The Thing Seeing Specification}

If an alternative formulation of epistemological disjunctivism is still to count as a version of epistemological disjunctivism, it will need to be a specification of the Core Thesis, which, it will be remembered, is the following:

The Core Thesis

In paradigmatic cases of perceptual knowledge an agent, $S$, has perceptual knowledge that $\phi$ in virtue of being in possession of rational 
support, $R$, for her belief that $\phi$ which is both factive (i.e. R's obtaining entails $\phi$ ), and reflectively accessible to $S$.

So what can we offer?

There is a lemon before me. It seems to be part of common sense to suppose that rational support for beliefs about the lemon before me can come from my plainly seeing $i$. Suppose I know, by vision, that the lemon before me is yellow. We can think of the visual basis of this knowledge in terms of my seeing the yellow lemon. How do I know that the lemon is yellow? Because I see it. So one option to explore here is whether Good Case rational support can come from states of the form seeing $x$ (or seeing an $F$ thing).

I want to explore this idea now. To be clear, what we are focusing on is what we might put in terms of a specification of the Core Thesis, something like this (again with the restriction to vision):

\section{The Thing Seeing Specification}

The particular kind of rational support that the epistemological disjunctivist claims that our beliefs enjoy in paradigm cases of perceptual knowledge is that provided by visual perceptual states of the form seeing $x$ (or seeing an $F$ thing).

I'll make two general remarks about this specification and then consider a challenge concerning whether it can really be a specification of the Core Thesis.

The first thing to note here is that 'thing' is a dummy term, which is, as Dretske (1979) puts it, 'intended to cover such disparate items as tables, houses, cats, people, games, sunsets, signals, tracks, shadows, movements, flashes, and specks' (p. 98). The values that $x$ can take in states of the form $S$ sees $x$ (and $S$ sees an $F x$ ) are rich and varied: think of all of the different sorts of things or entities (particulars) that you can clap your eyes upon.

Second, in this specification we are not appealing to states of seeing that $p$ as such states are conceived on the standard view of seeing that $p$. And the states we are appealing to don't entail such states. Thus, this specification does differ from the Specification + The Standard View. One way to illustrate this is as follows. I see a yellow lemon, but I just don't form beliefs about the lemon's colour. Perhaps my attention is completely elsewhere (e.g., on the object to the side of the lemon, or some mathematical matter, or whatever). Thus, I don't see that the lemon is yellow. Or perhaps I am just not capable of making colour judgements concerning objects like lemons - so I certainly can't see that the lemon is yellow. But for all that, I can see the yellow lemon. 
And for similar reasons the perceptual states we are appealing to here don't entail states of knowledge. I can see a yellow lemon, and yet not know that the lemon is yellow. To know that the lemon is yellow I must believe that the lemon is yellow, and, as noted, the mere fact that I perceive the yellow lemon doesn't guarantee that I judge or believe that the lemon is yellow - I might not make anything, cognitively, of my perception. (For a richer defence of similar claims, see Dretske (1969)).

I've noted how states of seeing an $F$ thing don't amount to states of seeing that $p$ (as standardly conceived). Nor do they amount to or entail states of knowing that $p$. Thus a version of epistemological disjunctivism formulated in terms of the Thing Seeing Specification won't face the basis problem that the version of epistemological disjunctivism formulated in terms of the Specification + The Standard View faces.

\subsection{A Challenge Concerning Factivity}

But we need more by way of an assurance that the Thing Seeing Specification can genuinely be a specification of the Core Thesis. What more can we say about states of seeing an $F$ thing so as to appreciate how the Thing Seeing Specification can serve as a specification of the Core Thesis? As noted, I am bracketing issues to do with reflective accessibility here, so I will address only the factivity aspect of the Core Thesis. Accordingly, one thing we need to make sure of is that states of seeing an $F$ thing can constitute factive rational support for beliefs.

We can animate this question in the form of a challenge. On the face of it the states we are appealing to in the Thing Seeing Specification don't have a propositional structure. That is to say, they are not, on the face of it, propositional attitudes. (We are, after all, concerned with seeing in the sense of 'see' which doesn't take a propositional complement). We might then wonder how such states can constitute or provide rational support which is factive. For on one understanding of a factive mental state, it is a propositional attitude that one can have only to truths. Seeing that $p$ is such a mental state. It is a propositional attitude one can have only to a true content. But if seeing a yellow lemon, for instance, is not a propositional attitude, then it can't be a factive mental state in the technical sense just mentioned. How then can states of that sort constitute or provide factive rational support for beliefs? This a question we must answer if we want the Thing Seeing Specification to be a genuine specification of the Core Thesis.

One way to try to meet this challenge is by taking on substantive commitments regarding the nature of states in which one sees an $F$ thing, so that after 
all such states are able to constitute factive states in the technical sense. I consider a development of this line of thought in the next section, and a different line of thought in the section after.

\section{The Propositional Thing Seeing Approach}

One option here is to suggest that although on the face of it states of seeing a yellow lemon and the like are not propositional, they in fact really are propositional, in some sense. For once we start to do theoretical work in the philosophy of perception, we will see that states of seeing an $F$ thing have to be propositional in some sense. Even if not straightforwardly propositional, it might be argued that they have to at least constitutively involve propositional attitudes. One might think this, for instance, if one holds to (A) the natural idea that states of seeing either are perceptual experiences (of some sort), or at least are hybrid states which involve experiences (an experiential component), and (B) a propositional theory of perceptual experiences.

Take (A). When I see a yellow lemon, I have a visual experience. And this is part of what it is to see a thing. I'll understand this in terms of perceptual appearances: in seeing a thing, the thing I see must look some way or other to me. The specific experience I have - the specific perceptual appearance - is not determined merely by what I see and how it is. Just because I see a yellow lemon doesn't mean that my experience will be one in which it looks yellow to me (as opposed to, say, green). The point of (A) is just that if I see an $F x$ I must have some visual experience or other of $x$; it must look some way or other to me.

We might then ask how we are to understand such perceptual appearances, and here is where (B) comes in. A simple propositional theory of experience states that experiences are mental states which involve propositional contents and relations to those contents (see, e.g., Searle (1983)). An entity's appearing $F$ to one in perceptual experience is understood as a propositional attitude with the content, say, that is $F$. And further, it is understood as a propositional attitude in which that content is presented to one as true. Thus experiencing is a perceptual propositional attitude more like believing than, say, hoping, or desiring. (For a more detailed discussion of propositional views of perceptual experience see Martin (2002), Crane (2011), and Siegel (2011)).

With this background, a proponent of the Thing Seeing Specification can elaborate on the Thing Seeing Specification in the following way. They can say that when I know that the lemon before me is yellow on the basis of vision, the visual basis of this is a state of thing seeing, seeing a lemon. But it is to be understood richly as (or as involving) a sort of experience in which the thing I 
see looks yellow to me. This - the experience, or experiential component - is in fact a perceptual propositional attitude. The experience is a state in which I visually experience that that [the lemon before me] is yellow. So the states of thing seeing involved in paradigm cases of perceptual knowledge are well suited to qualify as a factive mental states in the technical sense, for they are (or involve) propositional attitudes.

But something more needs to be added here, namely, that the propositional attitudes which constitute such states of thing seeing are factive - essentially relations to true propositions. So, in a case where I see a yellow lemon and this grounds my knowledge that the lemon before is yellow, and where we think of this in terms of visually experiencing that it is yellow, me must understand this visual experience as one I can have only to a true content. It is a factive kind of visual experience, and thus not like the visual experiences we have in hallucinations. We can, if we chose, put this in McDowell's way. The perceptual appearances involved in such experiences are cases of facts making themselves manifest (McDowell (1982)). Some experiences which strike us as exactly the same, from the inside (e.g., hallucinations), are mere appearances.

So, on this propositional way of developing the Thing Seeing Specification - call it the Propositional Thing Seeing Approach - the perceptual states of the sort mentioned in the Thing Seeing Specification do involve or are propositional attitudes. And, moreover, they involve or are factive propositional attitudes. Experiences understood as such are obviously well suited to constitute factive rational support, for they are factive mental states in the technical sense. Thus if we work out the Thing Seeing Specification in these terms, we can meet the factivity challenge, and we can see how the Thing Seeing Specification can be a genuine specification of the Core Thesis (so long as we get matters of reflective accessibility straight).

Does the Thing Seeing Specification developed along these lines collapse into either the Specification + The Standard View, or the Specification + the McDowell-Pritchard View? Here, as a reminder, are the different specifications we have distinguished

\section{The Specification}

The particular kind of rational support that the epistemological disjunctivist claims that our beliefs enjoy in paradigm cases of perceptual knowledge is that provided by seeing that the target proposition obtains. So when one has paradigmatic perceptual knowledge of a proposition, $p$, one's reflectively accessible rational support for believing that $p$ is that one sees that $p$. 
The Specification + The Standard View

The Specification + the Standard view of states of seeing that $p$ where that includes the Entailment Thesis.

The Specification + The McDowell-Pritchard View

The Specification + McDowell and Pritchard's understanding of states of seeing that $p$ where the Entailment Thesis doesn't hold.

Even if we insist that states of seeing an $F$ thing are to be understood in the rich, and propositional way discussed above, it is still not at all obvious why we should suppose that they are knowledge entailing. I can see a yellow lemon and my experience can be a factive propositional attitude in which I visually represent that that [lemon] is yellow, even if I don't know that it is yellow. Again, perhaps I am just not paying attention to relevant features of the scene, or perhaps I am not capable of making the relevant judgements, even though the fact that the lemon is yellow is shaping my visual consciousness. So the Thing Seeing Specification doesn't collapse into the Specification + The Standard View.

It is much less clear, however, why the Thing Seeing Specification, developed along these lines, doesn't collapse into the Specification + The McDowellPritchard View (for short, the McDowell-Pritchard Approach). For what more is there to $S$ 's being in a state of seeing that $p$, in the sense in which McDowell and Pritchard want to use the expression ' $S$ sees that $p$ ', than $S$ being in a state of thing seeing as that is cashed out on the above propositional theory? For McDowell, as we noted above, the idea of seeing that $p$ is run together with facts being made manifest to one in visual experience.

Let's grant that the visual perceptual states themselves - that is, those factive states which are the grounds of perceptual knowledge in paradigm cases of such knowledge - are conceived of in the same way, at the level of the nature of the states, by the proponent of the Propositional Thing Seeing Approach, and the proponent of the McDowell-Pritchard Approach. Accordingly, the approaches are, on that point, substantially the same.

But the positions are not exactly the same overall. For it makes a difference whether the visual perceptual states are thought of as states of thing seeing, or states of seeing that $p$. If we insist that they are states of seeing that $p-$ in the ordinary sense of 'sees that $p$ ' - as McDowell and Pritchard do, then we take on an extra commitment. As we've seen, this is the denial of the Entailment Thesis. And this is just what I questioned above. If, however, we stick with the formulation in terms just of thing seeing, with the details of the propositional theory, we don't take on this dubious commitment. On these grounds, then, 
the Propositional Thing Seeing Approach is to be preferred, it is less committed than the McDowell-Pritchard Approach.

Here, then, are the lessons of the discussion so far. When it comes to formulating epistemological disjunctivism it looks lie the Specification + The Standard View won't work - because of the basis problem. But then the Specification + The McDowell-Pritchard View is problematic too - because it involves the denial of the Entailment Thesis. Comparatively, and more constructively, it looks like the Propositional Thing Seeing Approach is to be preferred. And that is what I've argued so far.

But that is not the point on which I want to end. For I now want to suggest that there is an alternative way to develop the Thing Seeing Specification - that is, an alternative way for it to meet the factivity challenge - which is even better than the McDowell-Pritchard Approach, and the Propositional Thing Seeing Approach, in an important way: it simply doesn't involve a commitment to the metaphysics of experience involved in those two other approaches. I call this the 'Minimal Thing Seeing Approach'. I turn to this now.

\section{The Minimal Thing Seeing Approach}

A version of epistemological disjunctivism has to work out a way for the perceptual states which form the basis of paradigmatic perceptual knowledge to provide factive rational support. It makes sense, then, to get involved in thinking about the nature of the perceptual states in question. The views we've considered so far all try to work out how the perceptual states in question can themselves be (or involve) factive states in the technical sense of being factive propositional attitudes. The Propositional Thing Seeing Approach, and the McDowell-Pritchard Approach, thus take on substantive commitments in the metaphysics of perception. That is, they are committed to the view that there are some states of perception - that is, those involved in paradigmatic perceptual knowledge - which constitutively involve propositional representational content. The perceptual states in question are a species of representational state.

Taking on such metaphysical commitments in formulating one's epistemology of perception is perfectly acceptable if the commitments are obvious, or uncontentious, or unavoidable. But the particular commitment we've encountered here is none of the above. It is not obvious or uncontentious, it is a theoretical commitment which is denied by many. For instance, some want to resist representational theories of experience (see, e.g., Travis (2004), Kalderon (2011a,b), and Brewer (2011)). And others, though they endorse the idea that perceptual states are representational, want to resist the idea that they involve propositional 
or propositionally structured representation (see e.g., Burge (2010) and Crane (2011)).

Still, one might suggest that the commitment in question is just what one has to take on if one wants to be an epistemological disjunctivist. And this is exactly what I now want to question. I think it is plausible to suppose that we have to think about the nature of the relevant perceptual states if we are to develop the epistemological disjunctivist programme. But it is wrong to suppose that we must therefore take on the metaphysical commitment identified above. This is what the Minimal Thing Seeing Approach will allow us to appreciate. The idea is that there are facts about the nature of thing seeing, which are relatively theory neutral, but which mean that states of thing seeing can constitute factive states. How can we spell this out?

The key is to see how a state of thing seeing can constitute factive rational support for $p$ without being a factive mental state in the technical sense - where that would require it to be a propositional state. The way to see how this is possible is to note that seeing an $F$ thing is similar to seeing that a (the, that) thing is $F$, in this sense: $S$ cannot see an an $F$ thing if there isn't an $F$ thing there to be seen. Seeing a yellow lemon requires that there is a yellow lemon there to see. Seeing a yellow lemon may not be a factive mental state in the technical - propositional - sense, but even so, if $S$ sees a yellow lemon, then there must be a lemon which $S$ sees and it must be yellow. Thus, a formulation of epistemological disjunctivism in terms not of seeing that $p$ but in terms of seeing an $F$ thing can capture what is essential to the idea that Good Cases involve factive - truth-guaranteeing - rational support. A disjunctivist can say that a subject who sees the yellow lemon is, just like the subject who sees that the lemon is yellow, in a mental state (a seeing) the presence of which guarantees the truth of the belief (or beliefs) it rationally supports (that the lemon is yellow).

Understood in this way the Thing Seeing Specification is a genuine specification of the Core Thesis (again, assuming that we have matters of reflective accessibility straight). Suppose that $S$ has an item of paradigmatic perceptual knowledge. They know that that [lemon] is yellow. An epistemological disjunctivist can say that the rational support $R$ for this belief is constituted by their seeing a yellow lemon. $R$, the fact that $S$ sees a yellow lemon, entails that the lemon is yellow. Thus $R$ is rational support which is in its nature factive: $R$ could not obtain in a situation in which the relevant content is false.

What I have just said draws on the following idea we find in McDowell

if a perceptual state can consist in a subject's having a feature of her environment perceptually present to her, that gives lie to the assumption that a perceptual state cannot warrant a belief in a way 
that guarantees its truth. If a perceptual state makes a feature of the environment present to a perceiver's rationally self-conscious awareness, there is no possibility, compatibly with someone's being in that state, that things are not as the state would warrant her in believing that they are, in a belief that would simply register the presence of that feature of the environment (McDowell (2011, p. 31)).

Seeing a lemon there is a way for a lemon to be perceptually present to one. If it merely looks to one as if there is a lemon there, then a lemon is not perceptually present to one, but if one genuinely sees a lemon there, then a lemon is present to one. Thus that perceptual state can serve as a truth-guaranteeing warrant for a belief with the content: there is a lemon there. What I said above is an expansion of McDowell's idea, and we can put it alternatively like this: If one sees a yellow lemon, then, in the McDowellian idiom, there is no possibility, compatibly with someone's being in that perceptual state, that things are not as the state would warrant her in believing that they are in a belief that would involve the attribution of the feature in question to the object in question. Thus such perceptual states can serve to constitute factive rational support, even if they are not themselves factive mental states in the technical sense.

What is doing the work here is that seeing an $F x$ requires the existence of an $F x$. (It is in this respect that seeing is just like standing next to a thing. If I stand next to a red postbox, then there must be a red postbox there which I stand next to). This - the idea that seeing is subject to an existence condition - is not a special theoretical point about seeing, it is just a basic point about the logic or structure of states seeing, which all sides can agree on. And it is this which enables us to assuage the challenge regarding factivity, and see how the Thing Seeing Specification can be a genuine specification of the Core Thesis, without taking on a metaphysics of thing seeing on which it is a propositional representational state. That may be true, I am not suggesting that a proponent of the Thing Seeing Specification commits to a denial of that. The point is that it is not required to cash out how a formulation of epistemological disjunctivism in terms of thing seeing can meet the factivity challenge.

Now one might grant that an epistemological disjunctivist can answer the challenge concerning factivity in this more neutral way, yet claim that still some appeal to states of seeing having propositional content will need to be made in order to get other aspects of the epistemology of perception straight. I'll now describe one way of pressing this allegation.

Suppose that $S$ sees a yellow lemon, and on that basis comes to judge (and know) that it is yellow. In seeing the yellow lemon $S$ has factive rational support 
to believe that that is yellow (among other contents). But how does the specific content: that is yellow get singled out in $S$ 's cognitive space, so to speak, as a content to judge, as a content about which $S$ becomes knowledgable? If we take it that seeing the yellow lemon is a state with propositional content, and on an occasion the specific content that is yellow, we can explain this: the content is already present in perception. It is then taken up in cognition as a content of knowledge. But if all we have in the picture is merely that $S$ sees a yellow lemon, we lack a story about how $S$ comes to entertain the content: that is yellow. There doesn't seem to be anything about the structure of experience which enables us to see how $S$ comes to entertain the specific content in question.

One thing to say here is that it is not obvious that a defender of a propositional approach is really in any better position. For if we are considering seeing a thing, a yellow lemon, we need some explanation of how one's perceptual experience of the lemon comes to have a specific content (e.g., that is yellow). What is it about $S$, her situation, the conditions, the scene before her, etc which means that in seeing a yellow lemon she comes to propositionally represent it in a certain way (as, say, yellow)? It is not obvious how to answer this question. And it is also not obvious that whatever a defender of a propositional approach says here won't be able to be taken up in a more neutral framework, by way of explaining how perceptually based cognition gets to involve specific contents.

But a more direct way that a defender of the Minimal Thing Seeing Approach can deal with the challenge is to point out that it is misleading to claim that all we have in the picture is merely that $S$ sees a yellow lemon. For in seeing a yellow lemon $S$ has a visual experience, in which the lemon appears some way to her. That is part of what is involved in seeing a yellow lemon. What grounds which contents $S$ comes to entertain in seeing the yellow lemon is in part a function of how things appear to her in seeing the yellow lemon. A defender of the Minimal Thing Seeing Approach can suggest that $S$ comes to entertain the content that is yellow partly because of the way the lemon appears to her in her experience of it: namely, as yellow. So the minimal thing seeing theorist doesn't deny that there is an element to the structure of experience, a presentation or appearance of an object as being a certain way, which facilitates the singling out of a specific content in cognition.

A proponent of such an approach can flesh out the thing seeing specification in this manner. They can say that the states of perception which are involved in paradigmatic cases of perceptual knowledge are states of thing seeing, understood in this way: in a paradigmatic case of perceptual knowledge where $S$ knows that that is $F$ on the basis of vision, this is because $S$ sees an $F$ thing for what it is; where, that is, the $F$ thing appears $F$ to $S$. This is a minimal thing seeing approach because (a) the way in which the states of thing seeing 
are held to constitute factive rational support draws not on some commitment to a propositional theory of experience, but rather just to features of the logic of seeing which all sides can agree on, and (b) there is an appeal to perceptual appearances - which is again a non-theoretical aspect of the nature of seeingthough no appeal to a propositional theory of the nature of such appearances. The very idea of an experience in which a thing appears to a subject in a certain way may be accounted for in terms of a propositional view of experience. But such an account doesn't flow from the very idea of perceptual appearances.

\section{Conclusion}

How are we to formulate epistemological disjunctivism? If we understand epistemological disjunctivism in terms of the Core Thesis (see section (11)), then we have a number of alternatives (not all of which have been properly appreciated in the literature on epistemological disjunctivism up to this point):

1. The Specification + Standard View

2. The McDowell-Pritchard Specification

3. The Thing Seeing Specification

(a) The Propositional Thing Seeing Approach

(b) The Minimal Thing Seeing Approach

On the one hand we can go with the Specification + Standard View. But then, as Pritchard has argued, we run into the basis problem (see section (30). We might then go with the McDowell-Pritchard Specification, but this involves the dubious, or at the least unsupported denial of the Entailment Thesis (see sections (4) and (5)), and substantive commitments in the metaphysics of perception. We make progress by introducing a Thing Seeing Specification (see section (7)). But this can be understood in different ways too. The Propositional Thing Seeing Approach (section (8)) is an improvement on the McDowell-Pritchard Specification, for it is consistent with the Entailment Thesis. But it still involves the substantive commitments in the metaphysics of perception. In contrast, there is a Minimal Thing Seeing Approach (section (90)). This is preferable to all of the other approaches. For it doesn't run into a basis problem. It is consistent with the Entailment Thesis. And as I argued in the previous section it is a genuine specification of the Core Thesis which doesn't involve the substantive commitments in the metaphysics of perception we find in other approaches. 
Whether epistemological disjunctivism is true or not is a further question. But when trying to assess a philosophical position, we are much better off if we have a clearer idea of the different forms it can take - especially the more minimal forms. So I hope what I have done here can contribute significantly to future assessment of whether epistemological disjunctivism is true. In particular, I hope we can now see more clearly that the truth of epistemological disjunctivism doesn't hang on the full McDowellian inheritance. A version of it is still available even if we reject McDowell's metaphysics of perception, and even if we hold on to the standard view of seeing that $p$.

\section{References}

Brewer, Bill (2011). Perception and its Objects. Oxford: Oxford University Press. Burge, Tyler (2010). The Origins of Objectivity. Oxford: Oxford University Press. Cassam, Quassim (2009). "Knowing and seeing: Responding to Stroud's dilemma". In: European Journal of Philosophy 17.4, pp. 571-589.

Crane, Tim (2011). "Is Perception a Propositional Attitude?" In: The Admissible Contents of Experience. Ed. by Katherine Hawley and Fiona Macpherson. Blackwell, pp. 83-100.

Dretske, Fred (1969). Seeing and Knowing. London: Routledge.

- (1979). "Simple Seeing". In: Perception, Knowledge and Belief: Selected Essays. Ed. by Fred Drestske. Cambridge: Cambridge University Press, pp. 97-112.

French, Craig (2012). "Does Propositional Seeing Entail Propositional Knowledge?” In: Theoria 78.2, pp. 115-127.

- (2013). "Perceptual Experience and Seeing that p". In: Synthese 190.10, pp. 17351751.

Gisborne, Nikolas (2010). The Event Structure of Perception Verbs. Oxford: Oxford University Press.

Kalderon, Mark Eli (2011a). "Before the Law". In: Philosophical Issues 21.1, pp. 219_ 244.

— (2011b). “Color Illusion”. In: Noûs 45.4, pp. 751-775.

Martin, Michael G. F. (2002). "The Transparency of Experience". In: Mind and Language 17, pp. 376-425.

- (2006). “On Being Alienated”. In: Perceptual Experience. Ed. by Tamar Szabó Gendler and John Hawthorne. Oxford: Oxford University Press.

McDowell, John (1982). "Criteria, Defeasibility, and Knowledge". In: Proceedings of the British Academy 68, pp. 455-479. Reprinted in McDowell (1998). Page references in the main body to that version. 
McDowell, John (1993). "Knowledge by Hearsay". In: Knowing from Words. Ed. by B. K. Matilal and A. Chakrabarti. Vol. 230. Synthese Library. Dordrecht: Kluwer, pp. 195-224. Reprinted in McDowell (1998). Page references in the main body to that version.

- (1994). Mind and World. Cambridge, MA: Harvard University Press. Page references to the 1996 edition.

- (1995). "Knowledge and the Internal". In: Philosophy and Phenomenological Research 55.4, pp. 877-893. Reprinted in McDowell (1998). Page references in the main body to that version.

- (1998). Meaning, Knowledge, and Reality. Cambridge, MA: Harvard University Press.

- (2002). "Responses". In: Reading McDowell on Mind and World. Ed. by Nicholas H. Smith. London: Routledge, pp. 269-305.

- (2008). "The Disjunctive Conception of Experience as Material for a Transcendental Argument". In: Disjunctivism: Perception, Action, Knowledge. Ed. by Adrian Haddock and Fiona Macpherson. Oxford: Oxford University Press, pp. 376-389.

- (2011). Perception as a Capacity for Knowledge. Milwaukee, Wisconsin: Marquette University Press.

Pritchard, Duncan (2011). "Epistemological Disjunctivism and the Basis Problem”. In: Philosophical Issues 21.1, pp. 434-455.

- (2012). Epistemological Disjunctivism. Oxford: Oxford University Press.

Searle, John (1983). Intentionality. Oxford: Oxford University Press.

Siegel, Susanna (2011). "The Contents of Perception". In: The Stanford Encyclopedia of Philosophy. Ed. by Edward N. Zalta. Fall 2011.

Snowdon, Paul F. (2005). "The Formulation of Disjunctivism: A Response to Fish". In: Proceedings of the Aristotelian Society 105.1, pp. 129-141.

Travis, Charles (2004). “The Silence of the Senses”. In: Mind 113.449, pp. 5794.

Turri, John (2010). “Does Perceiving Entail Knowing?” In: Theoria 76.3, pp. 197206.

Williamson, Timothy (2000). Knowledge and its Limits. Oxford: Oxford University Press. 